\title{
Brain Metastases: quest on primary site
}

\author{
Prajapati J.A. ${ }^{\text {, }}$, Shah A.H. ${ }^{2}$, Trivedi P.P. ${ }^{3}$, Gami A.J. ${ }^{4}$, Vyas V.R. ${ }^{5}$, Gandhi J.S. ${ }^{6}$ \\ ${ }^{1}$ Dr. Jagdish Arvindbhai Prajapati, Fellow in onco-pathology, ${ }^{2}$ Dr. Ashini Hemal Shah, Assistant Professor, ${ }^{3}$ Dr. Priti Pinakin \\ Trivedi, Professor and Head of Department, ${ }^{4}$ Dr. Amisha Jigar Gami, Assistant Professor, ${ }^{5}$ Dr. Vibha Rasesh Vyas, Assistant \\ Professor, ${ }^{6}$ Dr. Jahnavi Sanjay Gandhi, Assistant professor, Dept. of Onco-pathology, The Gujarat Cancer and Research Institute, \\ Ahmedabad, Gujarat, India.
}

Corresponding Author: Dr. Ashini Hemal Shah, Department. Of Onco-Pathology, The Gujarat cancer and research institute, Ahmedabad-380016, Gujarat, India. Email: drashini_shah@yahoo.co.in

\begin{abstract}
Background: Secondaries of brain (Brain metastases, BM) are most common central nervous system (CNS) tumors and it may be initial manifestation of systemic malignancies. Histomorphology of brain metastatic tumors along with immunohistochemistry (IHC) will helpful in the detection of unknown primary site (UPS) of brain metastases. Aim: To evaluate unknown primary site of brain metastases with help of immunohistochemistry. Material and Method: This study was conducted at the department of onco-pathology of our institute. Five years data from 2014 to 2018 were obtained from online Laboratory Information System (LIS), department of onco-pathology of our institute. IHC was performed on basis of histomorphology. Results: Total 128 brain metastatic tumors were retrieved. Of which the present study have applied IHC on 107 cases and in remaining 21 cases, systemic malignancies were already diagnosed. Out of 107 cases, primary site was detected in $92.53 \%$ cases $(\mathrm{n}=99)$ and in $7.47 \%$ cases $(\mathrm{n}=8)$, not able to detect primary site even after IHC. Lung was the most common primary site detected $(n=73)$ followed Gastrointestinal tract (GIT, $n=9)$. Conclusion: Lung followed by breast are the most common primary malignancies for secondaries of brain (BM). Systemic approach using immunohistochemistry is really helpful in detection of unknown primary site of secondaries of brain (BM).
\end{abstract}

Keywords: Brain metastases, Central nervous system, Unknown Primary Site

\section{Introduction}

Secondaries of brain (BM) are most common and devastating condition of Central Nervous System (CNS). Metastatic tumours are the most common CNS neoplasms [1]. In western literature, brain metastases vastly outnumber primary brain tumors [2]. Due to underdiagnosis and inaccurate reporting, the incidence rate for brain metastases reported in the literature probable underestimate the true incidence [3,4]. Exact incidence is unknown, however, the incidence of $\mathrm{BM}$ according to population-based studies range 8.3 to 14.3 per 100,000 people [5].

The interval between diagnosis of the primary tumors and the CNS metastases is generally $<1$ year for lung carcinoma but can be multiple years for breast cancer and melanoma [6]. In adults, metastases to the brain most commonly arises from primary tumors of lung (50-60\%), breast (15-20\%), skin (melanoma) (5-10\%) and gastrointestinal tract (GIT) (4-6\%) [2,7]. With the emergence of newer and better imaging technique, confirmatory diagnosis of brain neoplasm by histopathology has become easier [8].

Manuscript received: $19^{\text {th }}$ November 2019

Reviewed: $29^{\text {th }}$ November 2019

Author Corrected: $4^{\text {th }}$ December 2019

Accepted for Publication: $9^{\text {th }}$ December 2019
However, up to $15 \%$ of all patients with secondaries of brain (BM) have no clearly detectable primary site despite an extensive evaluation $[2,9,10]$. A five-year data study was carried out to evaluate unknown primary site (UPS) of secondaries of brain (BM) with help of histomorphology, clinico-radiological findings wherever possible and developing algorithm of IHC markers on basis of histomorphology.

\section{Material and Method}

Setting: This study was conducted at the department of onco-pathology of our institute. Duration: Five years data from 2014 to 2018 were obtained from Online Laboratory Information System (LIS), department of onco-pathology of our institute.

Type of study: Retrospective study

Sampling method: The data of secondaries of brain were retrieved from Online Laboratory System (LIS). Inclusion criteria: Cases of brain metastases diagnosed on histomorphology were included with known and unknown primary site.

Pathology Update: Tropical Journal of Pathology \& Microbiology Available online at: www.medresearch.in 1008 |P a g e 
Exclusion criteria: Other cases of primary brain tumors were excluded from this study. Haematoxylin and eosin (H\&E) stained slides were reviewed.

The immunohistochemistry (IHC) was performed on formalin fixed paraffin sections (FFPS) by automated immune stainer (Benchmark XT Ventana, Ventana Medical Systems, Tucson AZ) using indirect method. The following antibodies were used from available resources at our institute: Cytokeratin 7 (CK7), Cytokeratin 20 (CK20), AE1, Cytokeratin 5/6 (CK5/6), Thyroid transcription factor 1 (TTF 1), CDX2, PAX 8, Leucocyte common antigen
(LCA), Hepatocyte Paraffin 1 (HepPar 1), Glypican 3, Melan A, OCT3/4, Epithelial membrane antigen (EMA) (Cell Marque), Carcinoembryonic antigen (CEA, Dako North America Inc.), Glial fibrillary acidic protein (GFAP), HMB-45, Placental alkaline phosphatase (PLAP), CA-125, Vimentin (Biogenex), p63, Estrogen receptor (ER), Progesterone receptor (PR), Human epidermal growth factor 2 (HER 2), CD 10 (Ventana).

Ethics: An ethical approval has been taken.

Statistical analysis: Data was analysed using Statistical Package for the Social Science (SPSS).

\section{Results}

During this 5 year period from 2014 to 2018, only 128 CNS tumors diagnosed histo-pathologically as secondary tumors from LIS were retrieved.

In this group of 128 patients, 92 were males and 36 were females. Male to female ratio is $2.5: 1$. The age range was from 22 year to 73 year as shown in Table 1 .

Table-1: Demographic details

\begin{tabular}{|l|c|c|c|}
\hline Age $($ year) & Male $(\mathbf{n}=\mathbf{9 2})$ & Female $(\mathbf{n}=\mathbf{3 6})$ & Total $(\mathbf{n}=\mathbf{1 2 8})$ \\
\hline Mean age & 54.50 & 54.88 & 54.88 \\
\hline Median age & 56.50 & 57 & 57 \\
\hline Maximum age & 73 & 70 & 73 \\
\hline Minimum age & 22 & 28 & 06 \\
\hline
\end{tabular}

Table-2: Histopathological diagnosis of metastatic CNS tumours with its primary site distribution

\begin{tabular}{|c|c|c|c|c|c|c|c|c|c|c|c|c|}
\hline \multirow{2}{*}{$\begin{array}{l}\text { Primary } \\
\text { site }\end{array}$} & & \multicolumn{11}{|c|}{ Histopathological diagnosis } \\
\hline & 刍 & 를 & 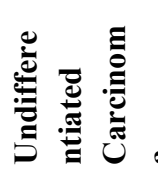 & $=$ & U & $\sum$ & 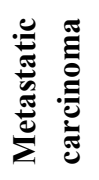 & 我总 & 0 & $\underset{U}{U}$ & 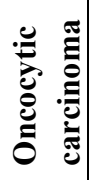 & $\stackrel{\text { जే }}{0}$ \\
\hline Lung & 56 & 4 & 1 & 2 & 6 & & 1 & 4 & & & & 74 \\
\hline Breast & 15 & & & & & & & & & & & 15 \\
\hline GIT & 10 & & & & 1 & & & 1 & & & & 12 \\
\hline Kidney & 3 & & & & & & 2 & & & & & 5 \\
\hline $\begin{array}{l}\text { Head \& } \\
\text { neck }\end{array}$ & & 1 & & & 1 & & & & 1 & & 1 & 4 \\
\hline Skin & & & & & & 4 & & & & & & 4 \\
\hline Liver & & & & & & & & & & 2 & & 2 \\
\hline Prostate & 2 & & & & & & & & & & & 2 \\
\hline $\begin{array}{l}\text { Pancreato } \\
\text { biliary }\end{array}$ & 2 & & & & & & & & & & & 2 \\
\hline Unknown & 3 & & & & 4 & & & 1 & & & & 8 \\
\hline Total & 91 & 5 & 1 & 2 & 12 & 4 & 3 & 6 & 1 & 2 & 1 & 128 \\
\hline
\end{tabular}

SCC-Squamous cell carcinoma, MM-Malignant melanoma, OS-Osteosarcoma, NE tumor-Neuroendocrine tumor HCCHepatocellular carcinoma 
Table-3: Distribution of primary sites $(n=128)$

\begin{tabular}{|l|c|c|c|}
\hline Primary site & $\begin{array}{c}\text { Number of cases } \\
(\mathbf{n = 1 0 7 )} \\
\text { (Unknown primary) (\%) }\end{array}$ & $\begin{array}{c}\text { Number of cases } \\
(\mathbf{n = 2 1 )} \text { (known case of } \\
\text { secondary malignancy) }\end{array}$ & $\begin{array}{c}\text { Total cases } \\
(\mathbf{n}=\mathbf{1 2 8})\end{array}$ \\
\hline Lung & $73(68.22)$ & 01 & 74 \\
\hline GIT & $09(8.42)$ & 03 & 12 \\
\hline Breast & $03(2.80)$ & 12 & 05 \\
\hline Kidney & $03(2.80)$ & 02 & 04 \\
\hline Head \& Neck & $03(2.80)$ & 01 & 04 \\
\hline Skin & $04(3.74)$ & & 02 \\
\hline Liver & - & & 02 \\
\hline Prostate & $02(1.87)$ & & 02 \\
\hline Pancreatobilliary & $02(1.87)$ & & 08 \\
\hline Unknown site & $08(7.48)$ & $\mathbf{2 1}$ & $\mathbf{1 2 8}$ \\
\hline Total & $\mathbf{1 0 7}(\mathbf{1 0 0})$ & & 02 \\
\hline
\end{tabular}

Table-4: Algorithm for evaluation of brain metastases with unknown primary

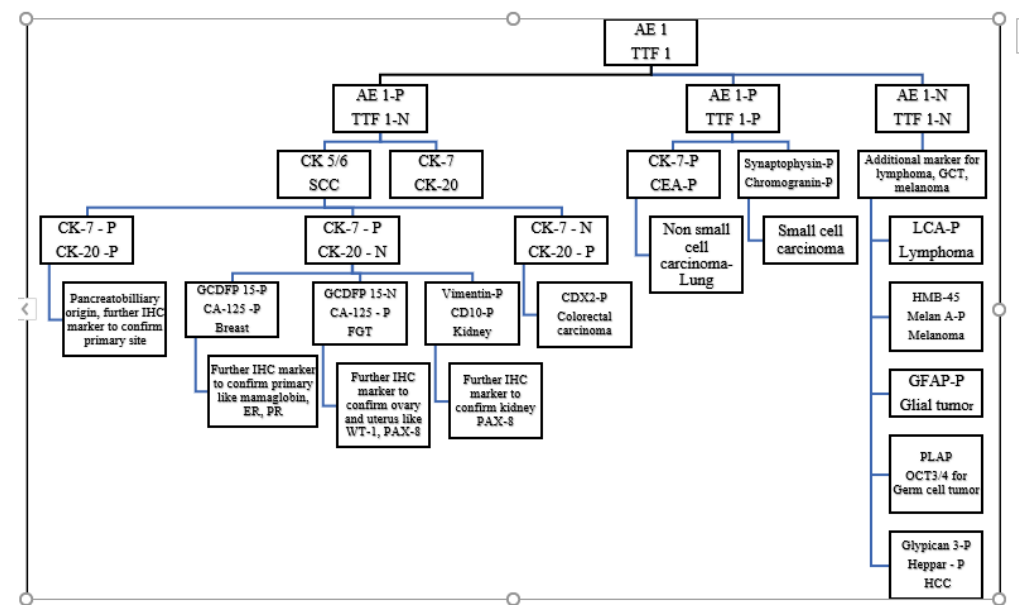

P-Positive, N- Negative, FGT- Female genital tract, GCT- Germ cell tumor

The distribution of the number of metastatic lesions was as follows: Single- 67\%, Multiple- 33\% (Figure 1).

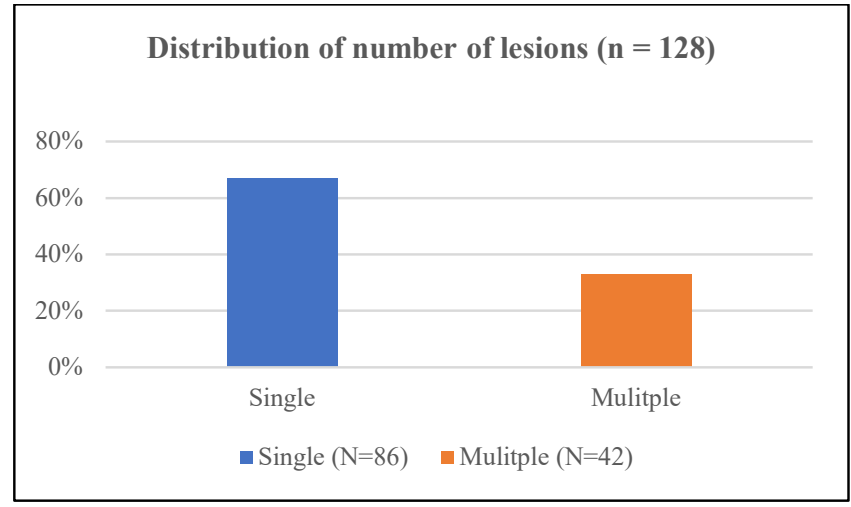

Fig-1: Distribution of number of lesions $(n=128)$.

The anatomical sites of metastatic lesions in brain were cerebrum $(78.91 \%)$, cerebellum $(14.06 \%)$, both cerebrum and cerebellum in $(6.25 \%)$ and skull vault $(0.78 \%)$. In the cerebrum, most common site was frontal $(21.13 \%)$ followed by parietal $(19.14 \%)$, occipital (20.79\%) and temporal (17.85\%). 
The $\mathrm{H} \& \mathrm{E}$ stained slides were evaluated and various histomorphological diagnosis were made as shown in Table 2. In present study, immunohistochemical stains were applied in 107 cases of metastases of unknown origin and from that detection of primary sites in 99 cases (92.53\%) and 8 cases (7.47\%) primary was unknown. In remaining 21 cases of brain metastases, systemic malignancies were already diagnosed. (Table 3 )

\section{Discussion}

Brain metastases is defined as tumour that originates outside the CNS and spread via the haematogenous route to the CNS or (less frequently) directly invades the CNS from adjacent anatomical structures. [11,12,13,14,15]. Autopsy studies have reported that CNS metastasis occur in about $25 \%$ of patients who die of cancer [12]. Secondaries of brain (BM) usually occurs late during the course of malignancy. The large majority of metastases arise from carcinomas and only $3 \%$ of patients with sarcoma develop metastases as reported by a study $[7,10]$.

The incidence of brain metastasis has been reported to be highest among patients diagnosed with primary lung cancer at an age of 40-49 years with primary melanoma, renal cancer or colorectal cancer at an age of 50-59 years and with breast cancer at an age of 20-39 years [3]. Metastatic brain tumors are more common in adults with their incidence peaking in the age group of 5080 years $[16,17,18]$. In present study median age was 57 year and mean age was 54.88 year which was comparable to the literature. Age range from 22 to 73 years which was comparable to other studies $[8,19]$.

Metastases in CNS can be seen in cerebral hemispheres (80\%), cerebellum (10-15\%), brain stem (2-3\%), spinal cord, bones, dura mater, leptomeninges, pituitary and choroid plexus. Metastatses in cerebellum are commonly from colorectal, uterine and renal carcinomas. The spinal epidural metastases most commonly are from the prostate, breast, lung, kidney $[12,13,14,15]$. In present study cerebral metastases were most commonly observed in 101 cases $(78.91 \%)$ followed by cerebellum in 18 cases (14.06\%). In cerebral hemisphere, frontoparietal area is most commonly involved in 40 cases $(39.60 \%)$ which was comparable to Subramanian A et al [20].

Multiple brain lesions are more suspicious for brain metastases [21]. Lung cancer and melanoma are more likely to be associated with multiple lesions whereas breast, thyroid, renal and colorectal carcinoma present with a solitary metastatic lesion $[9,22]$. In present study, it was observed that distribution of number of lesions single in 86 cases $(67 \%)$ and multiple 42 cases (33\%). This finding was comparable with Gupta et al [19], noted single lesions in $81.2 \%$ and multiple in $18.7 \%$.

In general, the primary tumors which serve as sources of BM are those arising in the lung, breast, skin, kidney and gastrointestinal tract (GIT) $[2,7,23,24,25]$. In present study, out of 107 cases of unknown primary site of brain metastases, $73(68.22 \%)$ cases had a primary site in the lung followed by gastrointestinal tract 9 cases $(8.42 \%)$, skin 4 cases $(3.74 \%)$ and breast 3 cases $(2.80 \%)$. These findings were comparable with other studies like Sharma $\mathrm{P}$ et al [26], Le Chevalier et al [27] and Stoier et al [28] noted primary in lung in $68.9 \%, 45.2 \%$ and $29 \%$ respectively.

In present study, metastatic adenocarcinoma was observed in 91 cases $(71.09 \%)$ followed by metastatic squamous cell carcinoma 12 cases $(9.37 \%)$ which was comparable to Patnayak et al [8] noted 26 cases (65\%) of metastatic adenocarcinoma and Gupta et al [19] noted 22 cases (68.7\%) of metastatic adenocarcinoma. Lung was most common source of metastatic adenocarcinoma with 56 cases followed by gastrointestinal tract 10 cases.

Only a few small series examine CNS metastasis from sarcomas, emphasizing their relative varity. The most common histologic subtypes include Osteosarcoma, pleomorphic undifferentiated sarcoma, Ewing's sarcoma and leiomyosarcoma [13,29,30,31]. In present study, one case of osteosarcoma already diagnosed primary site of head neck origin having brain metastases were noted.

Microscopically first step is to differentiate between the primary CNS tumor and metastases, followed by evaluate the tumor for morphology and architectural pattern like nested, glandular, trabecular, hepatoid, papillary, solid pattern. Presence of keratin material with squamous cells in dirty necrotic background suggest squamous cell carcinoma.

Presence of glandular pattern with cells having vesicular nuclei and prominent nucleoli suggest adenocarcinoma (Figure 2 and 3). Presence of monomorphic cells suggest lymphoid neoplasm and neuroendocrine origin tumor. Presence of mucinous material, brown pigmentation and colloid material are also helpful.

Pathology Update: Tropical Journal of Pathology \& Microbiology Available online at: www.medresearch.in 1011 |P a g e 


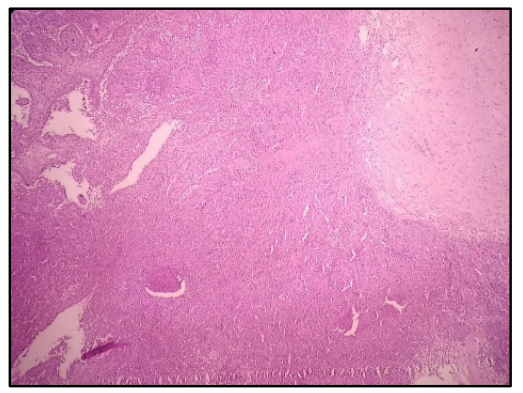

Fig-2: Metastatic adenocarcinoma deposit with adjacent brain parenchyma (H\&E 40x).

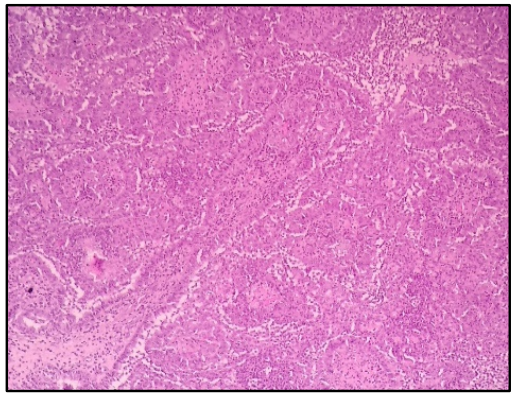

Fig-3: Metastatic deposit of adenocarcinoma (H\&E 100x).

In recent era, IHC is most important tool to diagnose and to evaluate UPS of brain metastases. A basic IHC panel is widely accepted initial step in difficult and UPS cases such as GFAP (glioma), CK and EMA (carcinoma), S-100 (melanoma, glioma), synaptophysin, chromogranin and NSE (neuroendocrine tumors), LCA (lymphoma), HMB-45 (melanoma), ER and PR (breast carcinoma) and PSA (prostate carcinoma) $[8,32]$.

The present study have used combination of several antibodies on a basis of histomorphology which is useful in evaluation of UPS. Thyroid transcription factor-1 (TTF-1) is a useful marker to identify lung as the primary site of tumor origin with its positivity rate of 78\% noted by Srodon and Westra et al [33], 67\% noted by Bohinski et al [34] and 78\% noted by Sharma P et al [26]. Normal brain tissue and astrocytic tumors do not stain with TTF-1. Thus TTF-1 is an important marker in primary panel with fact keep in mind that lung is the most common primary in cases with unknown primary. TTF-1 negativity can rule out lung as a primary site and simultaneously other primary sites also needs to be thought about. Diagnosis of breast carcinoma is made with help of GCDFP 15, ER, PR and HER 2. Positivity for CA-125 and Vimentin and CEA negativity favors ovarian carcinoma. In present study, primary panel of immunohistochemical markers were applied on a basis of histomorphology in 107 cases of UPS of brain metastases and from that detection of primary sites in 99 cases $(92.53 \%)$ and in 8 cases $(7.47 \%)$ primary was unknown even after IHC. From above findings it can be proposed that an algorithm for evaluation of UPS of brain metastases. (Table 4) Limitation of present study was that even after IHC markers primary site was remained unknown in 8 cases (7.47\%) and cost effectiveness of IHC markers. Patnayak et al [8] has observed that primary site remained unknown in $47 \%$ of cases with metastatic adenocarcinoma in brain. Sharma P et al [26] observed that primary site could not be diagnosed in $14 \%$ of cases even with IHC.

\section{Conclusion}

Secondaries of brain (BM) contribute significantly to morbidity and mortality of patients. In recent studies the reported improvements in overall survival of patients with brain metastases may be attributable to its earlier detection of metastases.

\section{What the study adds to the existing knowledge?}

Advantage: Findings of present study was comparable with other studies. From present study, it was observed that a systemic approach, consist of histomorphological diagnosis, clinco-radiological findings whenever possible and immunohistochemistry to evaluate brain metastases is helpful in detection of unknown primary in majority of cases. With these, one can also be able to use limited number of IHC markers and thereby improves the survival patients with early detection of UPS.

\section{Author's contributions}

Dr. Jagdish Arvindbhai Prajapati: Concept, study design, manuscript preparation

Dr. Ashini Hemal Shah: Statistical analysis 
Dr. Priti Pinakin Trivedi: Study design

Dr. Amisha Jigar Gami: Review and preparation of Manuscript

Dr. Vibha Rasesh Vyas: Data analysis, Manuscript preparation

Dr. Jahnavi Sanjay Gandhi: Manuscript preparation

Funding: No funding sources

Conflict of interest: None declared

Ethical Approval: This study was approved by the Institutional Ethics Committee

\section{References}

1. Suki D. The epidemiology of brain metastases. In: Sawaya R, editior. Intracranial metastases; current management strategies. Malden (MA): Blackwell; 2004. pp 20.

2. Patchell RA. The management of brain metastases. Cancer Treat Rev. 2003;29 (6):533-540. doi:10.1016 /s0305-7372 (03) 00105-1.

3. Bouffet E, Perilongo G, Cancete A, Massimino M. Intracranial ependymomas in children: a critical review of prognostic factors and a plea for cooperation. Med Pediatr Oncol. 1998. 30 (6):319-331. https://doi.org/10.1023/ A:1012590505236.

4. Fox BD, Cheung VJ, Patel AJ, Suki D, Rao G. Epidemiology of metastatic brain tumors. Neurosurg Clin N Am. 2011;22(1):1-6. doi: 10.1016/j.nec.2010.08.007.

5. Nayak L, Lee EQ, Wen PY. Epidemiology of brain metastases. Curr Oncol Rep. 2012;14(1):48-54. doi: 10.1007/s11912-011-0203-y.

6. Schouten LJ, Rutten J, Huveneers HA, Twijnstra A. Incidence of brain metastases in a cohort of patients with carcinoma of the breast, colon, kidney and lung and melanoma. Cancer. 2002;94 (10):2698-2705. doi:10.1002 /cncr.10541.

7. Wen PY, Loeffler JS. Brain metastases. Curr Treat Options Oncol. 2000;1(5):447-458. doi:10.4103/21527806.111299 .

8. Patnayak R, Jena A, Vijaylaxmi B, Lakshmi AY, Prasad $\mathrm{BCM}$, Chowhan AK et al. Metastasis in central nervous system: Clinicopathological study with review of literature in a tertiary care center in South India. South Asian J Cancer. 2013;2 (4):245-249. doi:10.4103/2278-330X. 119885.

9. Nussbaum ES, Djalilian HR, Cho KH, Hall WA. Brain metastases. Histology, multiplicity, surgery, and survival. Cancer. 1996;78(8):1781-1788.
10. Lagerwaard FJ, Levendag PC, Nowak PJ, Eijkenboom WM, Hanssens PE, Schmitz PI. Identification of prognostic factors in patients with brain metastases: A review of 1292 patients. Int J Radiat Oncol Biol Phys. 1999;43(4):795-803. doi:10.1016/s0360-3016 (98)00442-8.

11. Ascierto PA, Simeone E, Giannarelli D, Grimaldi AM, Romano A, Mozzillo N. Sequencing of BRAF inhibitors and ipilimumab in patients with metastatic melanoma: a possible algorithm for clinical use. J Transl Med. 2012; 10:107. doi: 10.1186/1479-5876-10-107.

12. Gavrilovic IT, Posner JB. Brain metastases: epidemiology and pathophysiology. J Neurooncol. 2005;75 (1):5-14. doi:10.1007/s11060-004-8093-6.

13. Salvati M, Frati A, Russo N, Brogna C, Piccirilli M, D'Andrea $G$ et al. Brain metastasis from prostate cancer. Report of 13 cases and critical analysis of the literature. J Exp Clin Cancer Res 2005;24(2):203-207.

14. Nathoo N, Chahlavi A, Barnett GH, Toms SA. Pathobiology of brain metastases. J Clan Pathol. 2005;58 (3):237-242. doi:10.1136/jcp.2003.013623.

15. Mut M, Schiff D, Shaffrey ME. Metastasis to nervous system: spinal epidural and intramedullary metastases. J Neurooncol. 2005;75(1):43-56. doi:10.1007/s11060-0048097-2.

16. Takakura K, Sano K. Clinical features of intracranial metastatic tumors. In: Takakura K, Sano K, Hojo S, Hirano A, editors. Metastatic tumors of the central nervous system. Tokyo-New York: Igaku-Shoin. 1982:112-137. doi: 10. 4103/0028-3886.232333.

17. Graus F, Walker RW, Allen JC. Brain metastases in children. J Pediatr 1983;103 (4):558-561. doi: https://doi.org /10.1016/ S0022-3476 (83) 80583-6.

18. Jemal A, Bray F, Center MM, Ferlay J, Ward E, Forman D. Global cancer statistics. CA Cancer J Clin. 2011;61(2): 69-90. doi:10.3322/caac.20107.

19. Gupta A, Chaturvedi S, Jha D, Chaturvedi M. Revisiting metastatic central nervous system tumors with unknown primary using clinicopathological findings: A single neurosciences institutional study. Indian $\mathrm{J}$ Pathol Microbiol. 2019;62(3):368-374. doi: 10.4103/IJPM. IJPM $592 \_18$.

20. Subramanian A, Harris A, Piggott K, Shieff C, Bradford R. Metastases to and from the central nervous system-the 'relatively protected site'. Lancet Oncol. 2002;3(8):498507. doi:10.1016/s1470-2045(02)00819-7. 
21. Kamar FG, Posner JB. Brain metastases. Semin Neurol. 2010; 30:217-235. doi: 10.1055/s-0030-1255225.

22. Delattre JY, Krol G, Thaler HT, Posner JB. Distribution of brain metastases. Arch Neurol. 1988;45(7):741-744. doi: 10.1001/archneur.1988.00520310047016.

23. Sawaya R, Bindal RK, Lang FF, Abi-Said D. Metastatic brain tumors. In: Kaye AH, Laws Jr ER, editors. Brain tumors. An encyclopedic approach. London: Churchill Livingstone. 2001;999-1026.

24. Weinberg JS, Lang FF, Sawaya R. Surgical management of brain metastases. Curr Oncol Rep. 2001;3(6):476-83. doi:10.1007/s11912-001-0068-6.

25. Graf AH, Buchberger W, Langmayr H, Schmid KW. Site preference of metastatic tumours of the brain. Virchows Arch A Pathol Anat Histopathol. 1988;412 (5):493-498. doi:10.1007/bf00750584.

26. Sharma P, Trivedi P, Shah MJ. Evaluation of central nervous system metastases with immunohistochemistry correlation. Indian J Pathol Microbiol. 2014;57(3):376-379. doi: 10.4103/0377-4929.138719.

27. Le Chevalier T, Smith FP, Caille P, Constans JP, Rouesse JG. Sites of primary malignancies in patients presenting with cerebral metastases. a review of 120 cases. Cancer. 1985;56 (4):880-882. doi:10.1002/1097-0142 (19850815) 56:4<880::aid-cncr2820560430>3.0.co;2-i.

28. Stoier M. Metastatic tumors of the brain. Acta Neurol Scand. 1965; 41:262-278.
29. Bindal RK, Sawaya RE, Leavens ME, Taylor SH, Guinee VF. Sarcoma metastatic to the brain: results of surgical treatment. Neurosurg. 1994;35(2):185-190. doi:10. 1227/00006123-199408000-00002.

30. Gercovich FG, Luna MA and Gottlieb JA. Increased incidence of cerebral metastases in sarcoma patients with prolonged survival from chemotherapy. Report of cases of leiomyosarcoma and chondrosarcoma. Cancer. 1975;36 (5):1843-1851. doi:10.1002/1097-0142 (197511) 36:5 $<1843$ ::aid-cncr2820360541>3.0.co;2-v.

31. Yoshida S, Morii K, Watanabe M, Saito T. Brain metastasis in patients with sarcoma: an analysis of histological subtypes, clinical characteristics, and outcomes. Surg Neurol. 2000;54(2):160-164. doi:10.1016 /s0090-3019 (00)00293-7.

32. Pekmezci M, Perry A. Neuropathology of brain metastases. Surg Neurol Int. 2013;4(4):245-255. doi:10.4103/2152-7806.111302.

33. Srodon M, Westra WH. Immunohistochemical staining for thyroid transcription factor-1: a helpful aid in discerning primary site of tumor origin in patients with brain metastases. Hum Pathol. 2002;33(6):642-645. doi:10. 1053/hupa.2002.124910.

34. Bohinski RJ, Bejarano PA, Balko G, Warnick RE, Whitsett JA. Determination of lung as the primary site of cerebral metastatic adenocarcinomas using monoclonal antibody to thyroid transcription factor-1. J Neurooncol. 1998;40(3):227-231. doi: https://doi.org/ 10.1023/A:10061 -02607697 .

\section{How to cite this article?}

Prajapati J.A., Shah A.H., Trivedi P.P., Gami A.J., Vyas V.R., Gandhi J.S. Brain Metastases: quest on primary site. Trop J Path Micro 2019;5(12): 1008-1014.doi:10.17511/ jopm.2019.i12.07 